\section{SUCCESSFUL USE OF TRANSESOPHAGEAL ECHOCARDIOGRAPHY DURING EXTRACORPOREAL MEMBRANE OXYGENATION IN INFANTS AFTER CARDIAC OPERATIONS}

We report the use of transesophageal echocardiography in infants after cardiac operations while supported on extracorporeal membrane oxygenation. In all patients transesophageal echocardiography provided valuable information when standard transthoracic echocardiographic evaluation was limited by poor acoustic windows. This report describes the application of transesophageal echocardiography during extracorporeal membrane oxygenation after cardiac operations. (J THORAC Cardiovasc Surg 1995;109:846-8)

Barry Marcus, MD, James B. Atkinson, MD, Pierre C. Wong, MD, Anthony C. Chang, MD, Winfield J. Wells, MD, George G. Lindesmith, MD, and Vaughn A. Starnes, MD, Los Angeles, Calif.
Extra tracorporeal membrane oxygenation (ECMO) offers lifesaving support in pediatric patients with severe cardiopulmonary failure after cardiac surgery. ${ }^{1-7}$ Transthoracic echocardiography is generally the diagnostic modality of choice to evaluate postoperative residua or ventricular function in a child after cardiac surgery. There are instances, however, when transthoracic acoustic windows are limited by an open sternum, chest wall bandages, or mediastinal air after the operation. The use of transesophageal echocardiography (TEE) in children has been established for intraoperative evaluation of cardiac operations, intensive care unit assessment, interventional cardiac catheterization, and selected outpatient evaluations. ${ }^{8-15}$ We report the use of TEE for anatomic and physiologic assessment in infants during ECMO after cardiac operations.

\section{Patients}

CASE 1. A 12-day-old girl weighing $2.8 \mathrm{~kg}$ with Dtransposition of the great arteries, large secundum atrial septal defect, large inlet muscular ventricular septal defect, and patent ductus arteriosus underwent an arterial switch operation, closure of atrial and ventricular septal defects, and division of patent ductus arteriosus. The patient was successfully weaned from cardiopulmonary

From the Division of Pediatric Cardiology, Department of Pediatric Surgery, and the Division of Cardiothoracic Surgery, Children's Hospital of Los Angeles, University of Southern California School of Medicine, Los Angeles, Calif.

Received for publication April 19, 1994.

Accepted for publication August 9, 1994.

Address for reprints: Barry Marcus, MD, Box 34, Division of Pediatric Cardiology, Children's Hospital of Los Angeles, 4650 Sunset Blvd., Los Angeles, Calif. 90027

Copyright $(\mathcal{O} 1995$ by Mosby-Year Book, Inc.

0022-5223/95\$3.00+ $0 \quad \mathbf{1 2 / 1 / 5 9 9 5 9}$ bypass. However, after infusion of fresh frozen plasma, an acute anaphylactoid reaction occurred with diffuse erythema and associated hypotension. After resuscitative efforts, TEE assessment revealed severe global biventricular dysfunction, and ECMO was instituted for myocardial support. Complete TEE evaluation of intracardiac and great vessel anatomy and ventricular function was performed $^{16,17}$ after the patient had been rewarmed and weaned from cardiopulmonary bypass but before decannulation and sternal closure. TEE was performed with a $6.8 \mathrm{~mm}$ tip biplane pediatric (Toshiba) probe with twodimensional imaging, M-mode, and pulsed Doppler and Doppler color flow mapping capabilities connected to a Toshiba SSH-140A ultrasound system (Toshiba American Medical Systems Inc., Tustin, Calif.). Because of cardiac edema, the sternum was not closed and the wound was covered with a silicone patch (Mentor Corporation, Goleta, Calif.). Serial TEE evaluations at 24 and 48 hours of ECMO initially revealed persistently poor biventricular function, but 48 hours after the operation left ventricular function appeared markedly improved, prompting decannulation of the ECMO. During weaning to decannulation while the patient was receiving inotropic and afterload reduction pharmacologic support, continuous TEE monitoring of cardiac function revealed normal ventricular function on discontinuation of ECMO support. Subsequently, the sternum was closed and predischarge transthoracic echocardiographic evaluation revealed normal biventricular function.

CASE 2. A 10-day-old boy weighing $3.8 \mathrm{~kg}$ with $\mathrm{D}$ transposition of the great arteries, large muscular ventricular septal defect, and mitral accessory chordae extending across the left ventricular outflow tract underwent an arterial switch operation, patch closure of the large muscular ventricular septal defect, and resection of accessory mitral valve chordae. Intraoperative TEE after repair revealed a structurally intact repair with depressed left ventricular function. Because of hemodynamic instability and cardiac edema, the sternum was left open and the wound was covered with a silicone patch. Hypotension with decreased cardiac output led to ECMO support 4 hours after the operation. The patient's condition was stabilized by ECMO, but an attempt to wean at 36 hours was unsuccessful because of poor cardiac output. Echo- 
cardiographic reevaluation was performed with particular interest in the coronary artery connections. Transthoracic echocardiography was inadequate because of limited acoustic windows, but TEE again demonstrated coronary artery anastomoses to the aorta to be widely patent without kinking or distortion. No residual outflow tract obstruction or arterial stenosis was apparent, but a large pericardial effusion had developed and left ventricular function was poor. Surgical drainage of the pericardial effusion led to an immediate improvement in hemodynamics with subsequent rapid weaning from ECMO and chest closure. Predischarge transthoracic echocardiographic evaluation demonstrated normal left ventricular function.

CASE 3. A 21/2-year-old boy weighing $13.3 \mathrm{~kg}$ had completion of Fontan cavopulmonary connection for hypoplastic left heart complex with a prior stage II palliative reconstructive operation. Intraoperative TEE diagnosed severe right ventricular dysfunction and tricuspid insufficiency immediately after the operation, necessitating ECMO support. The lateral tunnel cavopulmonary anastomoses were unobstructed. The sternum was left open, which precluded transthoracic echocardiographic assessment. Repeat TEE 5 days later during ECMO revealed improved right ventricular function allowing for successful discontinuation of ECMO and sternal closure. Predischarge transthoracic echocardiographic evaluation demonstrated right ventricular function to be normal.

\section{Methods}

All TEE studies were performed during the ECMO state, with the child mechanically ventilated, heavily sedated, and paralyzed. With the child supine, the head midline, and the jaw supported, the slightly anteriorly flexed, unlocked TEE probe was gently passed into the esophagus by means of a nonvisually directed technique. ${ }^{16}$ A complete TEE assessment ${ }^{16,17}$ was performed with focus on issues particularly pertinent to the previous operation, evaluation of ventricular function, and assessment for pericardial effusion.

\section{Results}

In all infants TEE allowed complete echocardiographic evaluation of the anatomic and physiologic results of surgical repair, and in each of these infants the repair was excellent. TEE revealed the problem requiring ECMO support in two infants to be that of a stunned myocardium, from which they gradually recovered, and in a third infant pericardial effusion was diagnosed by TEE, drained, and the child was rapidly weaned from ECMO thereafter.

\section{Discussion}

ECMO can support the patient with postbypass stunned myocardium and ventricular dysfunction, allowing gradual recovery of myocardial function. ${ }^{1-7}$ These patients often leave the operating room with an open sternum covered with a silicone dressing because of cardiac edema or have chest bandages or mediastinal air, any of which can limit transthoracic acoustic windows. ${ }^{12,18}$ When transthoracic echocardiographic assessment is suboptimal, the retrocardiac vantage point of TEE avoids these problems. TEE allows for assessment of intracardiac repair for postoperative residua and serial evaluation of ventricular function before and during ECMO decannulation to assess the myocardial response. TEE also provides immediate assessment of the adequacy of the cardiac repair during the operation, so that if the problem remains uncorrected the patient may be returned to cardiopulmonary bypass for further repair, ${ }^{8-11}$ without the need for ECMO.

Systemic anticoagulation, which is associated with ECMO support, is not a contraindication for TEE probe insertion or manipulation, ${ }^{19,20}$ and neither we nor others have found bleeding or a propensity for esophageal trauma to be a problem during the operation or in outpatients with prosthetic heart valves who are receiving anticoagulants. ${ }^{8-12,15,19}$ The short duration of our TEE studies (10 to 37 minutes) should not incur risk of esophageal thermal or pressure injury. ${ }^{20,21}$ If continuous monitoring beyond 1 hour was to be used, such as for serial evaluation of ventricular function during weaning from ECMO, we suggest periodically turning off the ultrasound system and passing the probe tip into the stomach to avoid the risk of esophageal thermal and pressure injury. The smallest patient in whom we have inserted this particular pediatric TEE biplane probe weighed $2.8 \mathrm{~kg}$. The lower limit for patient weight depends on the specific size of the pediatric TEE probe used. Probe sizes vary with the different manufacturers of ultrasonic equipment and use may also depend on operator experience. Precaution must be taken not to perform TEE in neonates with esophageal abnormalities such as tracheoesophageal fistula. None of the patients had complications, or problems with ECMO support, associated with TEE evaluation.

TEE can be a safe and valuable diagnostic tool during ECMO support and can direct timing of decannulation from ECMO.

\section{REFERENCES}

1. Saito A, Miyamura H, Kanazawa H, Ohzeki H, Eguchi S. Extracorporeal membrane oxygenation for severe heart failure after Fontan operation. Ann Thorac Surg 1993;55:153-5.

2. Raithel SC, Pennington DG, Boegner E, Fiore A, Weber TR. Extracorporeal membrane oxygenation in 
children after cardiac surgery. Circulation 1992; 86(Suppl):II305-10.

3. del Nido PJ, Dalton HJ, Thompson AE, Siewers RD. Extracorporeal membrane oxygenator rescue in children during cardiac arrest after cardiac surgery. Circulation 1992;86(Suppl):II300-4.

4. Ziomek S, Harrell JE, Fasules JW, et al. Extracorporeal membrane oxygenation for cardiac failure after congenital heart operation. Ann Thorac Surg 1992;54: 861-8.

5. Delius RE, Bove EL, Meliones JN, et al. Use of extracorporeal life support in patients with congenital heart disease. Crit Care Med 1992;20:1216-22.

6. Klein MD, Shaheen KW, Whittlesey GC, Pinsky WW, Arciniegas E. Extracorporeal membrane oxygenation for the circulatory support of children after repair of congenital heart disease. J THORAC CARDIOVASC SURG 1990;100:498-505.

7. Redmond CR, Graves ED, Falterman KW, Ochsner JL, Arensman RM. Extracorporeal membrane oxygenation for respiratory and cardiac failure in infants and children. J Thorac Cardiovasc Surg 1987;93: 199-204.

8. Weintraub R, Shiota T, Elkadi T, et al. Transesophageal echocardiography in infants and children with congenital heart disease. Circulation 1992;86:711-22.

9. Ritter SB. Transesophageal real-time echocardiography in infants and children with congenital heart disease. J Am Coll Cardiol 1991;18:569-80.

10. Stevenson JG, Sorensen GK, Gartman DM, Hall DG, Rittenhouse EA. Transesophageal echocardiography during repair of congenital cardiac defects: identification of residual problems necessitating reoperation. J Am Soc Echocardiogr 1993;6:356-65.

11. Muhiudeen IA, Roberson DA, Silverman NH, Haas GS, Turley K, Cahalan MK. Intraoperative echocardiography for evaluation of congenital heart defects in infants and children. Anesthesiology 1992;76:165-72.

12. Wolfe LT, Rossi A, Ritter SB. Transesophageal echocardiography in infants and children: use and importance in the cardiac intensive care unit. J Am Soc Echocardiogr 1993;6:286-9.
13. van der Velde ME, Perry SP, Sanders SP. Transesophageal echocardiography with color Doppler during interventional catheterization. Echocardiography 1991;8:721-30.

14. Stumper O, Witsenburg M, Sutherland GR, CrommeDijkhuis A, Godman MJ, Hess J. Transesophageal echocardiographic monitoring of interventional cardiac catheterization in children. J Am Coll Cardiol 1991;18:1506-14.

15. Marcus B, Steward DJ, Khan NR, et al. Outpatient transesophageal echocardiography with intravenous propofol anesthesia in children and adolescents. J Am Soc Echocardiogr 1993;6:205-9.

16. Seward JB, Khandheria BK, Oh JK, et al. Transesophageal echocardiography: technique, anatomic correlations, implementation, and clinical applications. Mayo Clin Proc 1988;63:649-80.

17. Seward JB, Khandheria BK, Edwards WD, Oh JK, Freeman WK, Tajik AJ. Biplanar transesophageal echocardiography: anatomic correlations, image orientation, and clinical applications. Mayo Clin Proc 1990;65:1193-213.

18. Marcus B, Wong PC, Wells WJ, Lindesmith GG, Starnes VA. Transesophageal echocardiography in the postoperative child with an open sternum. Ann Thorac Surg 1994;58:235-6.

19. Daniel WG, Erbel R, Kasper W, et al. Safety of transesophageal echocardiography: a multicenter study of 10,419 examinations. Circulation 1991;83: 817-21.

20. O'Shea JP, Southern JF, D'Ambra MN, et al. Effects of prolonged transesophageal echocardiographic imaging and probe manipulation on the esophagus-an echocardiographic-pathologic study. J Am Coll Cardiol 1991;17:1426-9.

21. Urbanowicz JH, Kernoff RS, Oppenheim G, Parnagian E, Billingham ME, Popp RL. Transesophageal echocardiography and its potential for esophageal damage. Anesthesiology 1990;72:40-3. 